\title{
Erratum zu: Partizipatives Gesundheitsmanagement in der flexiblen Produktion: Entwicklung und Evaluation des teambezogenen Präventionskonzeptes SePIAR
}

\author{
Anja Gerlmaier ${ }^{1}$ \\ Online publiziert: 7. Juli 2021 \\ (c) Der/die Autor(en) 2021
}

\section{Erratum zu:}

Z. Arb. Wiss. 2020

https://doi.org/10.1007/s41449-020-00236-5

Der Artikel Partizipatives Gesundheitsmanagement in der flexiblen Produktion: Entwicklung und Evaluation des teambezogenen Präventionskonzeptes SePIAR von Anja Gerlmaier wurde ursprünglich Online First ohne „Open Access“ auf der Internetplattform des Verlags publiziert. Die Autorin hat sich jedoch nachträglich für eine „Open Access“-Veröffentlichung entschieden. Das Urheberrecht des Artikels wurde deshalb in (C) Der/die Autor(en) 2021 geändert.

(C) Der/die Autor(en) 2021

Die Online-Version des Originalartikels ist unter https://doi.org/ 10.1007/s41449-020-00236-5 zu finden.

Dr. Anja Gerlmaier

anja.gerlmaier@uni-due.de

1 Institut Arbeit und Qualifkation, Universität Duisburg-Essen, Forsthausweg 2, 47057 Duisburg, Deutschland

Open Access Dieser Artikel wird unter der Creative Commons Namensnennung 4.0 International Lizenz veröffentlicht, welche die Nutzung, Vervielfältigung, Bearbeitung, Verbreitung und Wiedergabe in jeglichem Medium und Format erlaubt, sofern Sie den/die ursprünglichen Autor(en) und die Quelle ordnungsgemäß nennen, einen Link zur Creative Commons Lizenz beifügen und angeben, ob Änderungen vorgenommen wurden.

Die in diesem Artikel enthaltenen Bilder und sonstiges Drittmaterial unterliegen ebenfalls der genannten Creative Commons Lizenz, sofern sich aus der Abbildungslegende nichts anderes ergibt. Sofern das betreffende Material nicht unter der genannten Creative Commons Lizenz steht und die betreffende Handlung nicht nach gesetzlichen Vorschriften erlaubt ist, ist für die oben aufgeführten Weiterverwendungen des Materials die Einwilligung des jeweiligen Rechteinhabers einzuholen.

Weitere Details zur Lizenz entnehmen Sie bitte der Lizenzinformation auf http://creativecommons.org/licenses/by/4.0/deed.de. 